\title{
LAKE SEDIMENT THICKNESS ESTIMATION USING GROUND PENETRATING RADAR
}

\author{
Sinam Reema Chanu ${ }^{1}$, R.K Chingkhei ${ }^{2}$, Manichandra Sanoujam ${ }^{3}$, Arun Kumar ${ }^{4}$ \\ ${ }^{1}$ Research Scholar, Department of Earth Sciences, Manipur University, Manipur, India \\ ${ }^{2}$ Research Associate, Department of Earth Sciences, Manipur University, Manipur, India \\ ${ }^{3}$ Scientist-C, Department of Earth Sciences, Manipur University, Manipur, India \\ ${ }^{4}$ Professor, Department of Earth Sciences, Manipur University, Manipur, India
}

\begin{abstract}
The objective of the study is to provide estimates of sediment thickness in Punem Lake, which is a shallow perennial lake in Manipur, India. Radar profiles are obtained in the lake with Mala GPR using $100 \mathrm{MHz}$ RTA (Rough Terrain Antenna). The average depth of the lake is found to be around $2.2 \mathrm{~m}$ with the total sediment thickness ranging from $2.2 \mathrm{~m}$ to $3.8 \mathrm{~m}$. For the present study two sediment layers are identified that can be easily differentiated from the GPR radargram and the thickness as well as the volume is calculated using ArcGIS. Minimum, maximum, and an average thickness of $0.02 \mathrm{~m}, 1.16 \mathrm{~m}$ and $0.50 \mathrm{~m}$ respectively is observed in the first layer with the majority of the thickest sediment deposits towards the North, Northeast and Eastern side of the lake. In the second layer a minimum, maximum, and an average thickness of $0.08 \mathrm{~m}, 0.99 \mathrm{~m}$ and $0.37 \mathrm{~m}$ respectively is observed with the majority of the thickest sediment deposits towards the North, Northeast and Western parts of the lake. Sediment volume of about 260303.33 cubic meters of deposit is estimated in the first layer of the lake bottom whereas that of the second layer is estimated to be about 188171.51 cubic meters only.
\end{abstract}

Keywords: Punem Lake, GPR, sediment thickness, sediment volume

\section{INTRODUCTION}

Sediment beneath lakes provides information about the history of environmental change in an area, as well as having an influence on the health of existing lakes. By understanding the type and extent of sediment packages beneath lakes, conclusions may be drawn about the chronology of geologic events that formed the lake and influenced its present conditions [1]. Sedimentation patterns are also affected by the amount of sediment supplied into the basin [2].

The present study aims to estimate the sediment thickness and volume of the sediment in Punem Lake using Ground Penetrating Radar (GPR). GPR is a geophysical technique that is widely used to study the shallow subsurface in a broad range of applications and environmental settings. GPR measures changes in the electromagnetic properties of subsurface features that cause reflection of transmitted electromagnetic waves [3]. GPR system consists of a transmitter that emits high frequency electromagnetic waves into the subsurface and receivers to record energy reflected from interfaces across which physical properties change. These physical properties are related to sediment composition and water content within the sediment. Part of the electromagnetic energy is scattered when the incident waves encounter an inhomogeneity in the subsurface, and wave energy reflected back up to the surface is detected by a receiving antenna. Factors that affect the maximum depth of penetration include the material type that the signal penetrates, the conductivity of the overlying material, and the frequency of the antenna used [4] [2].
The most common display of GPR data is one showing signal versus amplitude and is referred to as a trace. A single GPR trace consists of the transmitted energy pulse followed by pulses that are received from reflecting objects or layers. Several traces from the same location are typically stacked and averaged to provide better resolution of weaker reflections. A scan is a trace where a color or gray scale has been applied to the amplitude values. As the antenna is moved along a survey line, a series of traces or scans are collected at discrete points along the line. These scans are positioned side by side to form a display profile of the subsurface [5].

Moorman and Michel (1997) effectively used GPR in water depths upto $30 \mathrm{~m}$ and lake bottom sediment thicknesses of over 6m were delineated [6]. Delaney et al. (1992) mapped the distribution and thickness of lacustrine sediments [7]. Chanu et al (2013) profiled the sub-bottom of Punem Lake along with the bathymetric mapping using GPR. Deep horizontal continuous line, hyperbolic curve and shallow chaotic reflection are the primary features imaged by GPR [8].

\section{STUDY AREA}

Punem Lake (locally called Punem Pat) falls in Thoubal district of Manipur and it is located at about $20 \mathrm{~km}$ away from Imphal. The area of the lake is about $1.041 \mathrm{~km}^{2}$. It lies between the latitudes $24.67541^{\circ} \mathrm{N}$ to $24.68993^{\circ} \mathrm{N}$ and longitudes $93.97998^{\circ} \mathrm{E}$ to $93.99150^{\circ} \mathrm{E}$ (Fig.1). The area is covered by survey of India toposheet no. $83 \mathrm{H} / 14$ and $83 \mathrm{~L} / 2$ 
with $20 \mathrm{~m}$ contours interval (scale $-1: 50,000$ ). The Google image of Punem Lake is also shown in Fig.2.

The lake is a shallow perennial water body, bounded on other sides by two areas viz, Waithou Lake proper (Soirel) and Cheksabi Lake. The main feeder lines of the lake are the rivers draining down via Ningthibi Canal, the region of confluence of Imphal and Thoubal rivers. The morphometric as well as ecological survey indicate the advanced eutrophication going on in the lake.

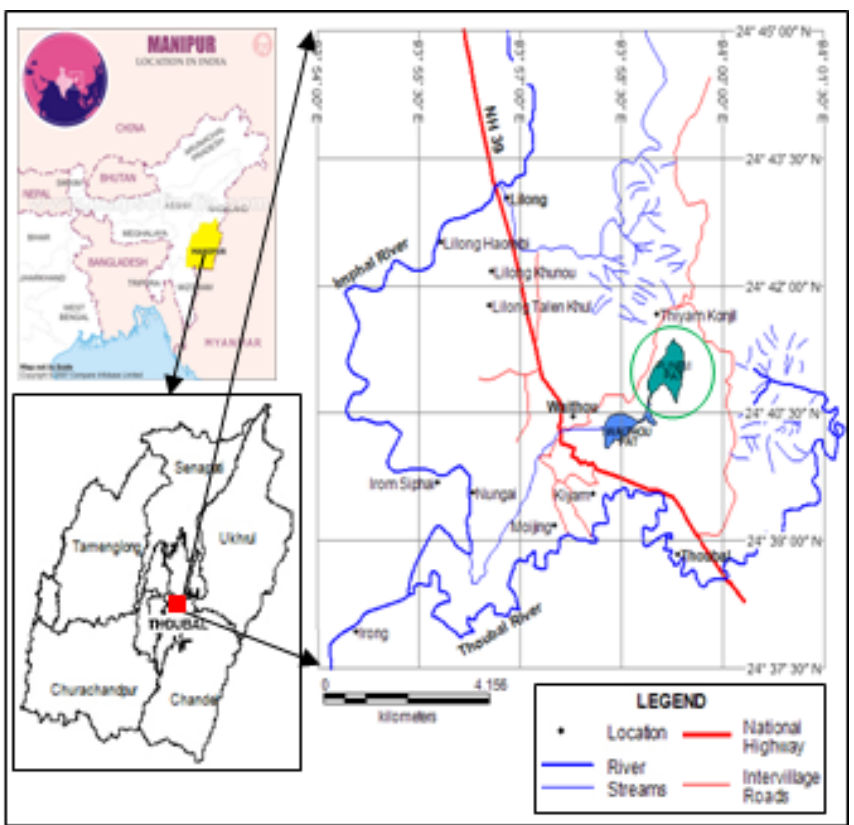

Fig -1: Location map of the study area

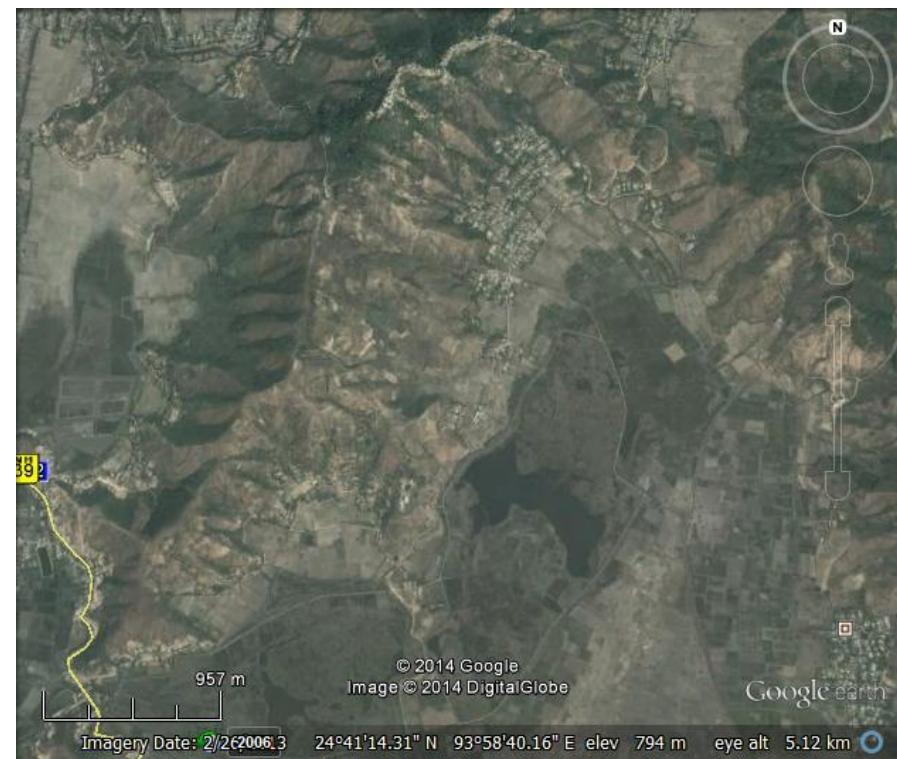

Fig. 2: Google map of the study area

\section{METHODOLOGY}

The present study adopts a standardised methodology using GPR technology in estimating the lake sediment thickness and volume. The major software used during the study includes RadExplorer for analysing the GPR data, MSExcel for intermediate GPR data processing, MapInfo for creating point data, Global Mapper for generating the Triangulated Irregular Network (TIN) Surface and ArcGIS for generation of sediment thickness map and estimation of sediment thickness and volume.

The generalized step followed in the study is given in the flow chart below (Fig 3).

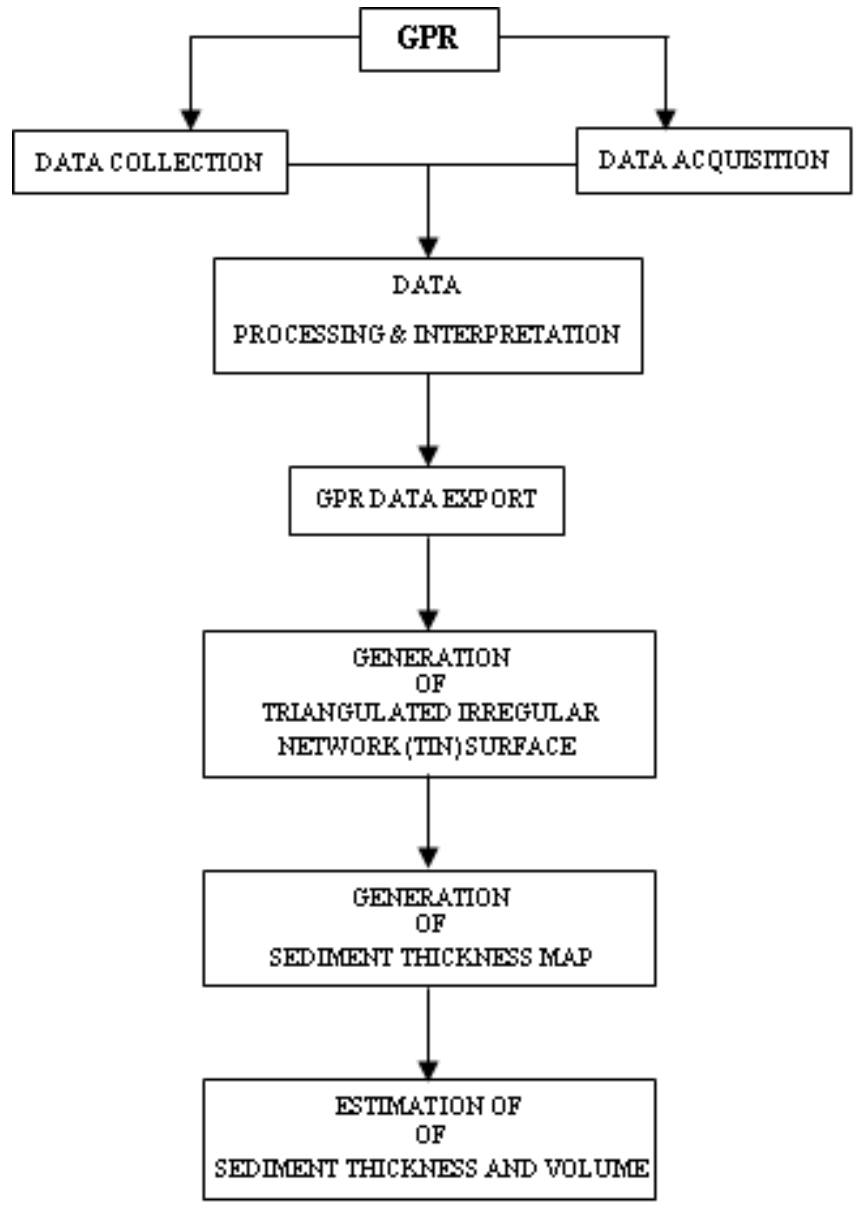

Fig -3: Flow chart of the steps followed in the study

\subsection{Data Collection}

Care has been taken while collecting the GPR data to cover maximum area of the lake in order to enable an estimation of the amount of sediment deposits and the volume (Fig. 5). The GPR system is synchronized with a USB communicated GPS, GM-158-USB so that the " $\mathrm{x}, \mathrm{y}, \mathrm{z}$ " coordinates is properly linked with GPR traces during profiling. The whole setup is placed in a boat except the $100 \mathrm{MHz}$ RTA (Rough Terrain Antenna) which is placed inside a PVC pipe so that the RTA remains directly on the water surface (Fig.4). The RTA is connected by fiber optics to the ProEx control unit. 


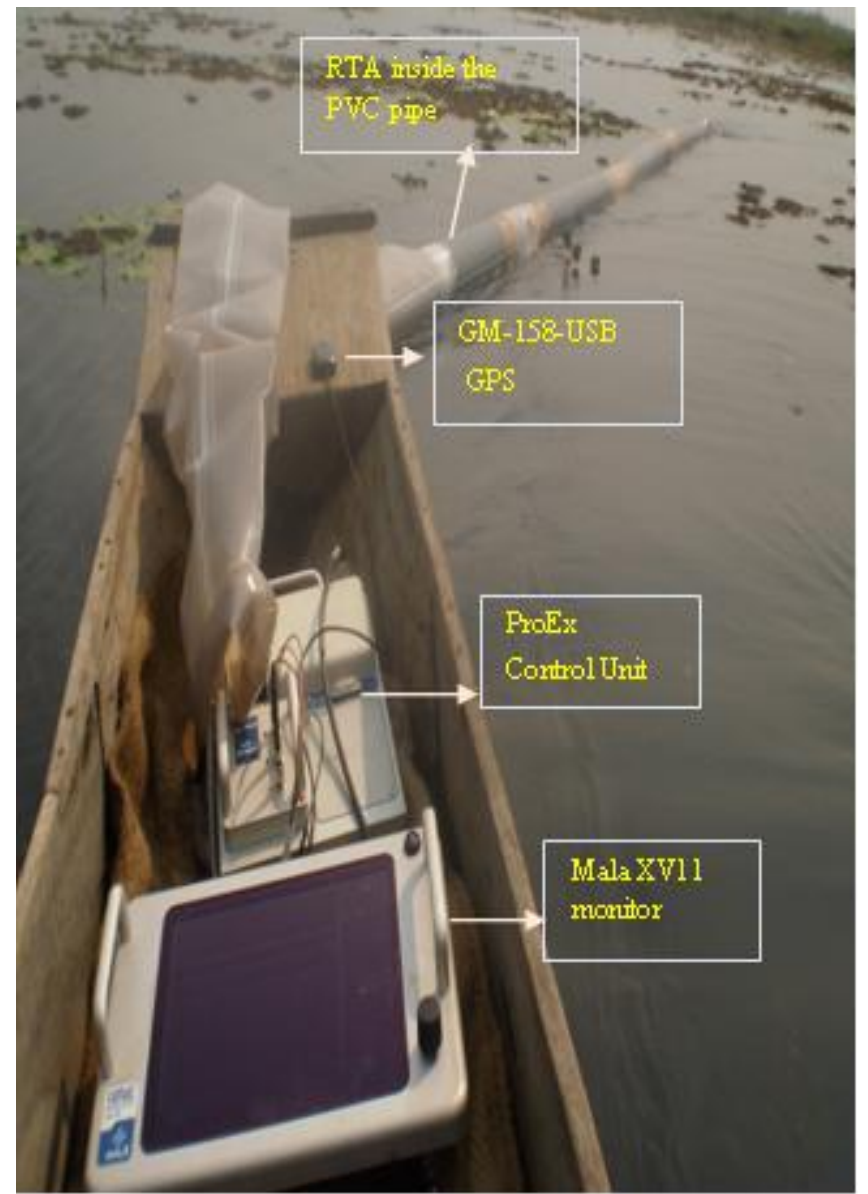

Fig -4: The Data collection with the complete GPR equipment

\subsection{Data Acquisition}

The acquisition mode is done with time triggered measurement. The time interval for recording the traces is set at $0.3 \mathrm{sec}$. The distance for the antenna separation is $2 \mathrm{~m}$. Number of samples is set between 1000 and 1200 which aimed for deeper penetration. Averaging the scans will keep the signal while attenuating the noise improving the signal to noise ratio [9]. Auto stacking is thus applied in order to get the best trade-off between signals to noise ratio.

\subsection{Data Processing and Interpretation}

The GPR data along with the GPS location points are processed and interpreted using appropriate software RadExplorer 1.4 from Mala Geosciences. Processing of the GPR data to enhance the image consisted of a few steps. First of all, main filters viz. DC Removal, background removal and bandpass filtering are applied. The DC Removal routine is meant to remove constant component of the signal in case there is one. The most intensive signal received by the ground-penetrating radar is the signal that arrives directly from the transmitting antenna - a direct wave. Background removal filter is applied to remove any instrument noise present that blocks the desired signal. Bandpass filter is also applied to the data in order to increase the signal/noise ratio.
The zero adjustment is adjusted to get the zero-depth at the first peak. For the configuration $3.4 \mathrm{~cm} / \mathrm{ns}$ speed is given in between the antennas. We can get the correct penetrated depth only when the proper velocity of the background (in the present study the epsilon $=81$ ) is put which is done under the model part in the RadExplorer. To obtain the $\mathrm{x}, \mathrm{y}, \mathrm{z}$ value of a particular point/ line a pick is used which is set to fill and peak automatically. The output format is saved as RAMAC/GPR which is supported by the programme. After the GPR data are processed and interpreted, two distinct layers could be identified that are used for the sediment thickness and volume analysis. The table of these two layers are then exported as text file and later on converted into ".csv" files in MS Excel. In order to maintain the accuracy of the proposed study, only the valid GPR traces that are properly synchronized with the GPS coordinates are used. The GPR transects/ traces used for the present study are shown in Fig. 5. The ".csv" is then used in the subsequent analysis.

\subsection{Sediment Thickness Map Generation}

Sediment thickness of both the layers that could be easily identified from the GPR data are analyzed using the Triangulated Irregular Network (TIN) analysis. For this purpose the following steps are followed.

Radar stratigraphic analysis and ground truthing of the GPR transects is done. Using MapInfo 10.5, the GPS location data from the ".csv" files of the two layers are separately first created as points with the depth attribute generated using GPR. While importing and generating point data from the ".csv" X co-ordinates and Y co-ordinates are correctly chosen with UTM (WGS 84) projection along with a UTM zone $46 \mathrm{~N}$. The point data thus generated is then reprojected to longitude/latitude (WGS 84) projection system for further study.

The reprojected point data of the two layers are then separately imported to Global Mapper to generate the Triangulated Irregular Network (TIN) surfaces. TIN is a form of vector based digital geographic data that is used for the representation of a surface. It is constructed by triangulating a set of vertices or points that are connected with a series of edges to form a network of triangles using various methods of interpolation viz. Delaunay triangulation or distance ordering [10]. In the present study the Delaunay triangulation method is used to generate the TIN surfaces. The TIN surface from global mapper is then exported as ".tif" for use in ArcGIS. The TIN surfaces in ".tif" format are then imported to ArcGIS to generate the sediment thickness maps.

In ArcGIS the corresponding sediment thickness maps of the identified layers are generated. In order to maintain the spatial extent of the lake area a common boundary of the lake is used while generating the sediment thickness maps. Further using this TIN derived sediment thickness map, volume of sediment deposit for each layer is also estimated. 


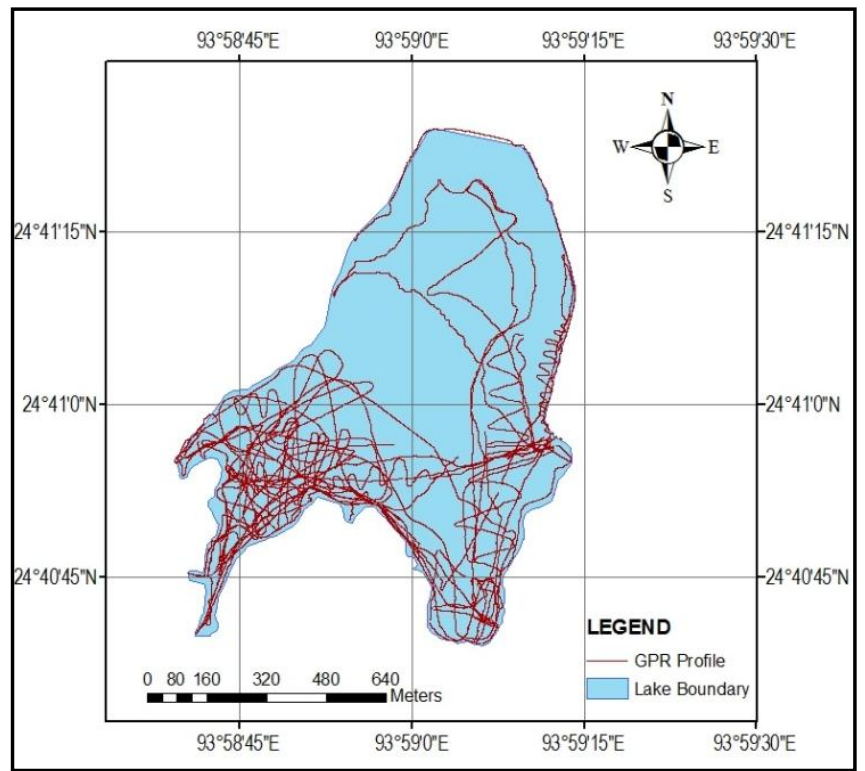

Fig -5: Map showing the GPR profiles in the Punem Lake

\section{RESULTS}

As per the set aim and objective of the present study the sediment deposit thickness and the corresponding volume of the sediment deposits are estimated. Accordingly, a minimum, maximum, and an average thickness of $0.02 \mathrm{~m}$, $1.16 \mathrm{~m}$ and $0.50 \mathrm{~m}$ respectively is observed in the first layer. The trend analysis of the sediment thickness of the first layer is done and indicates that the majority of the thickest sediment deposits are seen towards the North, Northeast and Eastern side of the lake (Fig.6).

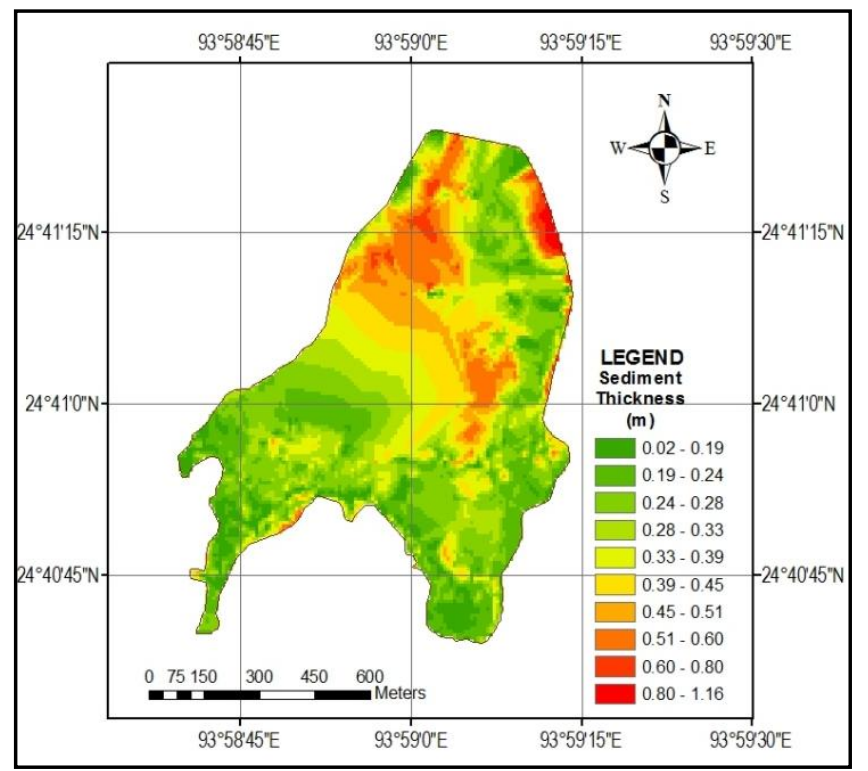

Fig -6: Sediment thickness map of first layer

Likewise in the second layer a minimum and maximum sediment thickness of $0.08 \mathrm{~m}, 0.99 \mathrm{~m}$ respectively with an average thickness of and $0.37 \mathrm{~m}$ is observed. The trend analysis of the sediment thickness of the second layer is also done and found that the majority of the thickest sediment deposits are seen towards the North, Northeast and Western parts of the lake (Fig.7).

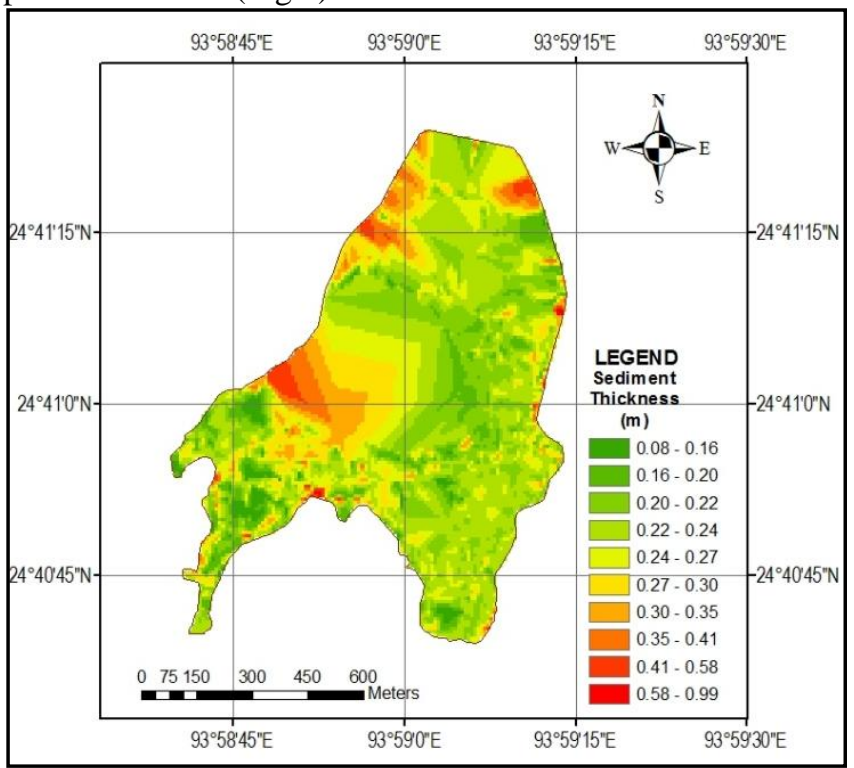

Fig -7: Sediment thickness map of second layer

Using the above sediment thickness maps the volumes of both the layers are also estimated. Thus, in the first layer a volume of about 260303.33 cubic meters of sediment deposit is estimated whereas that of the second layer is estimated to be about 188171.51 cubic meters only. This difference in volume of sediment deposit (about 72131.82 cubic meters) may be an indication of the ongoing process of sedimentation of the lake which is a time driven process before it becomes a distinctive layer in the future.

\section{CONCLUSIONS}

The Punem Lake, being surrounded by hills in almost all direction leads to continuous sediment deposition mainly during the rainy season. The higher sediment volume in the first layer i.e. the recent deposits may be an indication of this process. Further the use of GPR technology along with GIS software in the estimation of sediment thickness and volume of Lake Bottom is found to be very useful and time effective. The dating of the sediment is suggested so that a complete chronological picture of the lake sediment may be developed.

\section{REFERENCES}

[1]. Cedrone, K. (2012). Characterizing the sub-bottom geology at Andover Lake, CT using Ground-Penetrating Radar. Department of Environmental Earth Science, Eastern Connecticut State University, EES Report 480

[2]. Tang, Y. H. (2004). A multidisciplinary approach to studying lake level change, northern New Jersey. Theses and Dissertations, Lehigh University

[3]. Van Dam, R. L. (2001). Causes of Ground-Penetrating Radar reflections in sediment. Amsterdam, Vrije University [4]. Reynolds, J. M. (1997). An introduction to applied and environmental geophysics. West Sussex: John Wiley and Sons Ltd. 
[5]. Daniels, J. J. (2000). Ground Penetrating Radar Fundamentals. USEPA Region 5.

[6]. Moorman, B. J. and Michel, F. A. (1997). Bathymetric mapping and sub-bottom profiling through lake ice with ground-penetrating radar. Journal of Paleolimnology 18: 6173.

[7]. Delaney, A. J. (1992). Sub-bottom profiling: a comparison of short impulse radar and acoustic data: Geological Survey of Finland, Special Paper 16: 149-157.

[8]. Chanu, S.R., Kumar, A., Sanoujam, M. and Chingkhei, R.K. (2013). Bathymetric mapping and sub bottom profiling of Punem Lake using Ground Penetrating Radar. Golden Research Thoughts Vol.3, Issue-3. DOI:10.9780/22315063/332013/2829.

[9]. Bjorklund, N. and Johnsson, T. (2005). Real-time sampling of Ground Penetrating Radar and related processing. Master's Thesis, Lulea University of Technology, 2005:039 CIV-ISSN: 1402-1617- ISRN: LTUEX--05/039--SE.

[10]. ESRI (2012). ArcGIS Help. ArcGIS Resources. http://resources.arcgis.com/en/help/main/10.1/index.html\#// 006000000001000000 (dated: 30-08-2014) 